Original Research Paper

\title{
Telomere Length Measurement by Quantitative Real-time PCR: A Molecular Marker for Human Age Prediction
}

\author{
${ }^{1}$ Naglaa F. Alhusseini and ${ }^{2}$ Abdelmonem G. Madboly \\ ${ }^{1}$ Department of Medical Biochemistry, \\ ${ }^{2}$ Forensic Medicine and Clinical Toxicology \\ Faculty of Medicine, Benha University, Egypt
}

Article history

Received: 14-12-2015

Revised: $15-02-2016$

Accepted: 16-03-2016

Corresponding Author: Naglaa F. Alhusseini

Department of Medical

Biochemistry, Faculty of

Medicine, Benha University,

Egypt

Email: nagla.alhusseini@fmed.bu.edu.eg

\begin{abstract}
The fact that telomere shortening occurs with aging leads to the hypothesis that a correlation could be made between Telomere Length (TL) and suspect age. This study aimed to assess if TL can be used as an investigational tool to predict human age through developing a formula based on this correlation with accuracy suitable to be applied in forensic practice. A quantitative real-time PCR study was carried out on 80 Egyptians, ranging in age from 1-79 years. The results confirmed that the relative TL significantly shortened with aging; " $\mathrm{r} "=-0.903(\mathrm{p}<0.001)$. The human age could be determined by the following formula: $(\mathrm{Y}=66.9-$ 28X), (Y: Age in years; X: Relative TL), with a regression analysis between relative $T L$ and age had an $R^{2}=0.815$. The standard error of age estimate was \pm 10.14 years. The present study concluded that estimation of human age based on the relative TL measured by quantitative real-time PCR may be a useful method for age prediction, especially when there is no morphologic information in the biological samples, but the estimated standard error of age prediction in this study was quite high ( \pm 10 years) to be used with certainty in forensic investigations. Inter-individual variations in TL and variability among the gender must be also considered when applying this method. So, this method could only give a rough estimation of age and it may be a complementary method for age estimation from soft tissues.
\end{abstract}

Keywords: Telomere Length, Molecular Marker, Human Age Prediction, Quantitative Real-Time PCR, Egyptians

\section{Introduction}

In forensic practice, scientists compare unique genetic DNA profiles of individuals extracted from biological evidences found at crime scene with the DNA profile of suspects or with all profiles in a state or national databank (Kelly et al., 2013).

When there is no suspect to compare with, the scientist cannot help the investigators regarding what physical characteristics to look for in a suspect by using DNA profile, other than gender (Ballantyne, 2007).

It would be useful for the scientists to predict the outward appearance of an individual such as age, height, ethnicity, hair and skin color, by analyzing the DNA left behind in a crime scene to narrow down the range of suspects (Hewakapuge et al., 2008).
One important phenotypic characteristic is age of the suspect. Medical examiners have been able to determine the age of an individual by examining dental records and various features and measurements of the skeleton (Lynnerup et al., 2010).

A sample of biological evidence (e.g., a bloodstain) usually carries no morphological information. In this case, age estimation method on a molecular basis would be very useful (Karlsson et al., 2008).

There are four basic methods for estimation of the age of a person at the molecular level; deletions of mitochondrial DNA, shortening of telomeres, racemization of aspartic acid and Advanced Glycation End products (AGEs) (Meissner and Ritz-Timme, 2010).

Telomeres (from the Greek telos [end] and meros [part]) are DNA protein complexes at the ends of 
chromosomes, composed of tandem TTAGGG repeats ranging from few to 15 kilo bases in length. Telomeres play an essential role in the maintenance of genomic stability by protecting the ends of chromosomes from DNA damage (Thomas et al., 2008; Price et al., 2013).

Very little is known about the quantitative relationship between human Telomere Length (TL) and donor age. As a result, it is difficult to determine age by existing data. In addition, there is no research report of systemic population about telomere shortening (Takasaki et al., 2003; Ren et al., 2009).

Saeed et al. (2012) confirmed that it is necessary to design basic science experiments for better evaluation of the role of TL in molecular prediction of biological age, as it remains the most promising biomarker for this purpose.

As forensic biological samples may contain highly fragmented DNA molecules, analyzing telomere repeats using real-time Polymerase Chain Reaction (PCR) enables analysis of DNA of low concentration and partially degraded (Karlsson et al., 2008; Alaeddini et al., 2010).

Therefore, this study was conducted to assess the correlation between TL measured by a quantitative realtime PCR and human age, to see if TL can be used as an investigational tool for predicting human age through developing a formula (an equation) based on this correlation, with accuracy suitable to be applied in forensic practice.

\section{Subjects and Methods}

\section{Subjects}

This study was carried out on randomly selected 80 subjects, ranging in age from 1-79 years, with the following inclusion criteria: All are Egyptians, healthy with no history of any chronic diseases or tumors and unrelated (to exclude the effects of ethnicity and inheritance effects on telomere length).

Active smokers, obese or individuals on any kind of chronic medical treatment were excluded from the study (to exclude their effects on telomere length).

The subjects included in this study were stratified into a balanced sex distributed eight groups (each group had an equal numbers of males and females of corresponding ages) and each group comprised a 10years, representing each decade of life; $\{(\leq 1 \quad 0$ years $)$, (11-20 years), (21-30 years), (31-40 years), (41-50 years), (51-60 years), (61-70 years) and (71-80 years) $\}$.

Informed consent was taken from all subjects included in the study (from adults or from caretakers of minors); all subjects completed an in-person interview that ascertained information about the aim, general steps and scientific value of this study.
This study was approved by The Local Research Ethical Board of Faculty of Medicine, Benha University. All results were registered in special sheets of the study, which were confidential.

\section{Sampling:}

- Whole peripheral venous blood sample (about 3 $\mathrm{mL}$ ) was collected from each subject enrolled in the study, by trained nursing staff of Benha University Hospitals and put immediately in vaccutainer tubes containing EDTA

- Each sample was mixed and divided into two eppendorf tubes, stored at $-80^{\circ} \mathrm{C}$ for further processing

\section{Genomic DNA Extraction:}

- DNA was extracted using QIAamp DNA blood mini kit (Qiagen, Germany), following the manufacturer instructions

- The extracted DNA concentration was confirmed through measurement by NanoDrop 2000c Spectrophotometer, Thermo Scientific USA. Readings were taken at wave lengths of 260 and 280 $\mathrm{nm}$. Concentration of DNA sample was measured $=$ 50 ug $\mathrm{mL}^{-1} \times \mathrm{A} 260$ (Alhusseini et al., 2014)

\section{Quantitative Real time PCR:}

- The reference DNA sample was prepared from pooled sample. Four serial dilutions (with ten folds) were prepared and used in amplification plates as standards

- In ABI7900 fast real time machine (Applied Biosystems USA) the design of the plates was to measure Telomer Hexamer Repeat (THR) copy number in each individual sample and reference DNA diluted sample in the same plate in a conditions $95^{\circ} \mathrm{C}, 15 \mathrm{~min}$ for initial denaturation followed by 20 cycle of $95^{\circ} \mathrm{C}, 30 \mathrm{sec} ; 54^{\circ} \mathrm{C}, 1 \mathrm{~min}$; $72^{\circ} \mathrm{C}, 30 \mathrm{sec}$

- The same design of the previous plate was done in another plate for both Single Copy Gene (SCG) ${ }_{3} 6 \mathrm{~B}_{4}$ and housekeeping gene Human $\beta$-Globin (HBG) with conditions $95^{\circ} \mathrm{C}, 15 \mathrm{~min}$ for initial denaturation followed by 30 cycle of $95^{\circ} \mathrm{C}, 30$ sec; $58^{\circ} \mathrm{C}, 1 \mathrm{~min} ; 72^{\circ} \mathrm{C}, 30 \mathrm{sec}$. The primers used in these amplifications are described in Table 1. The master mix used in amplification was Super Real PreMix Plus (SYBR Green) TianGene BioTech

- The autosomal single copy gene ${ }_{3} 6 \mathrm{~B}_{4}$ gene, which encodes acidic ribosomal phosphoprotein PO, is 
located on chromosome No. 12 and we chose the ${ }_{3} 6 \mathrm{~B}_{4}$ gene, because it has already been validated for gene dosage studies (Boulay et al., 1999)

- There is no reliable method to directly measure Telomere Length (TL) in human cells (Ren et al., 2009). Measurement of relative TL depends on quntitation of THR copy number normalized to autosomal SCG copy number (Cawthon, 2002). The ratio between THR/SCG is proportional to the TL if the number of copies of SCG Cell ${ }^{-1}$ is the same in all individuals being studied

- To make sure that the numbers of cells were equal in each sample used, thereby we normalized the SCG quantity $\left(\mathrm{C}_{\mathrm{t}}\right.$ versus $\log$ flouresence $)$ to housekeeping gene quantity $\beta$-globin, $\Delta C_{t}{ }^{S C G} / \Delta C_{t}$ $\beta$-globin for all samples. It should be $1 \pm 0.05$. Since the TL was quantified as a ratio, the absolute TL in base pairs was not obtained. The relative TL was believed to reflect the actual differences in TL in individuals (Nakagawa et al., 2004)

\section{Statistical Design}

The collected data were organized, tabulated and analyzed using SPSS version 16 software (SPSS Inc, ILL Company, USA). Data were expressed as mean and standard deviation. Kolomogrov Smirnov test was used to assess the distribution of TL in different age groups, it was normally distributed $p>0.05$ in all age groups). Person's correlation coefficient (r), Student " $t$ " and ANOVA were used as tests of significance. Simple linear regression analysis was used to determine an equation to predict the age from the value of TL. The accepted level of significance in this study was at $\mathrm{p}<0.05$ (Dawson and Trapp, 1994).

\section{Results}

In the present study the relative telomere lengths of 80 Egyptian individuals aged from 1-79 years were measured using a quantitative real-time PCR method.

Correlation between Relative Telomere Length (TL)
and Age of the Individuals Included in the Study

The present work clearly illustrated that the relative TL of all individuals included in the study significantly shortened with aging, the correlation coefficient " $r$ " = $0.903(p<0.001)$, as shown in Fig. 1 .

When all samples were divided into eight age groups representing the decades of life, the results of the present study showed highly significant $(\mathrm{p}<0.001)$ decrease in mean relative $\mathrm{TL}$ among the different age groups, as illustrated in Fig. 2.

Table 1. The primers used in reference DNA amplifications (Alhusseini et al., 2014)

\begin{tabular}{lll} 
& $(5 '-3$ ') & \\
\hline Gene & Forward & Reverse \\
\hline THR & GGTTTTTGAGGGTGAGGGTGAGGGTGAGGGTGAGGGT & TCCCGACTATCCCTATCCCTATCCCTATCCCTATCC-CTA \\
${ }_{3} \mathrm{~B}_{4}$ & CAGCAAGTGGGAAGGTGTAATCC & CCCATTCTATCATCAACGGGTACAA \\
HBG & GCTTCTGACACAACTGTGTTCACTAGC & CACCAACTTCATCCACGTTCACC \\
\hline
\end{tabular}

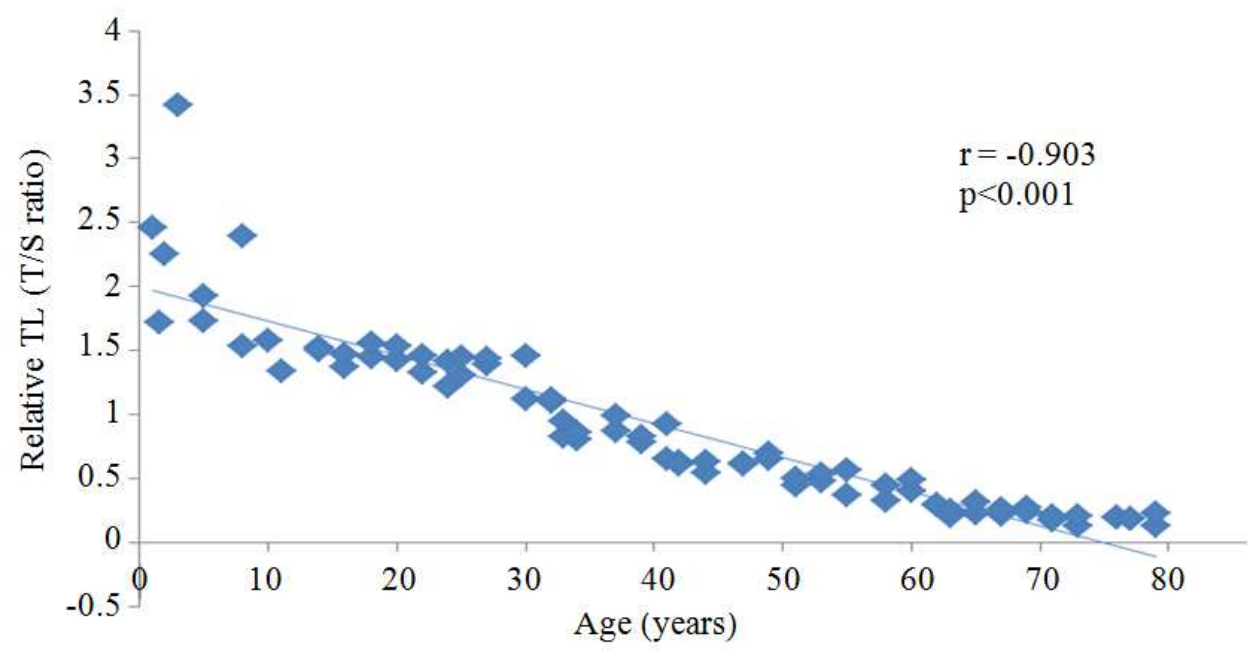

Fig. 1. Scatter plot showing the correlation between relative Telomere Length (TL) and age in all individuals included in the study (n $=80)$, aged from 1-79 years, $(r=-0.903)$ and $(\mathrm{p}<0.001)$ 


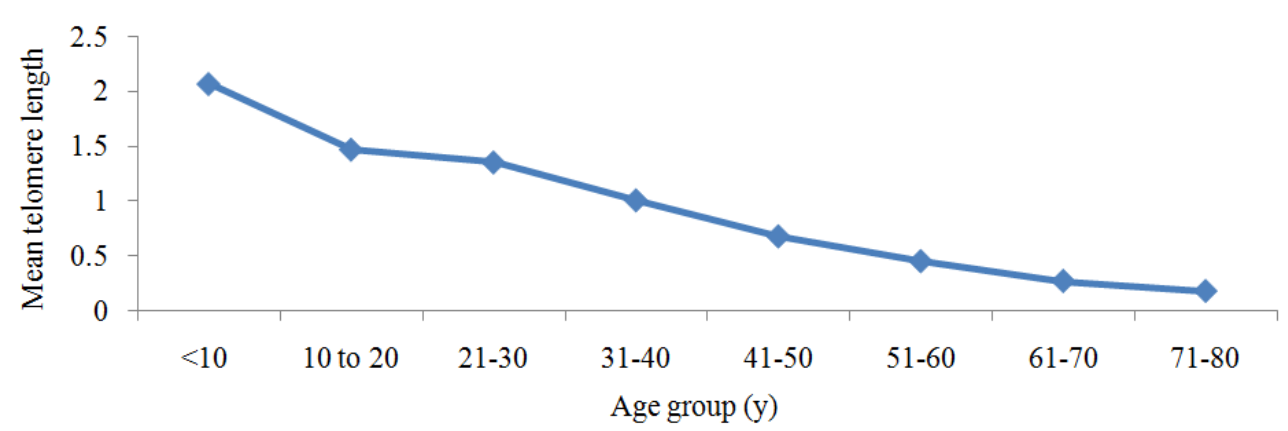

Fig. 2. Scatter plot showing the mean relative Telomere Length (TL) in relation to the age of individuals in different eight age groups (each group comprised 10-years, representing each decade of life). Results showed significant decrease of mean relative TL among the eight subgroups, $\mathrm{p}<0.001$

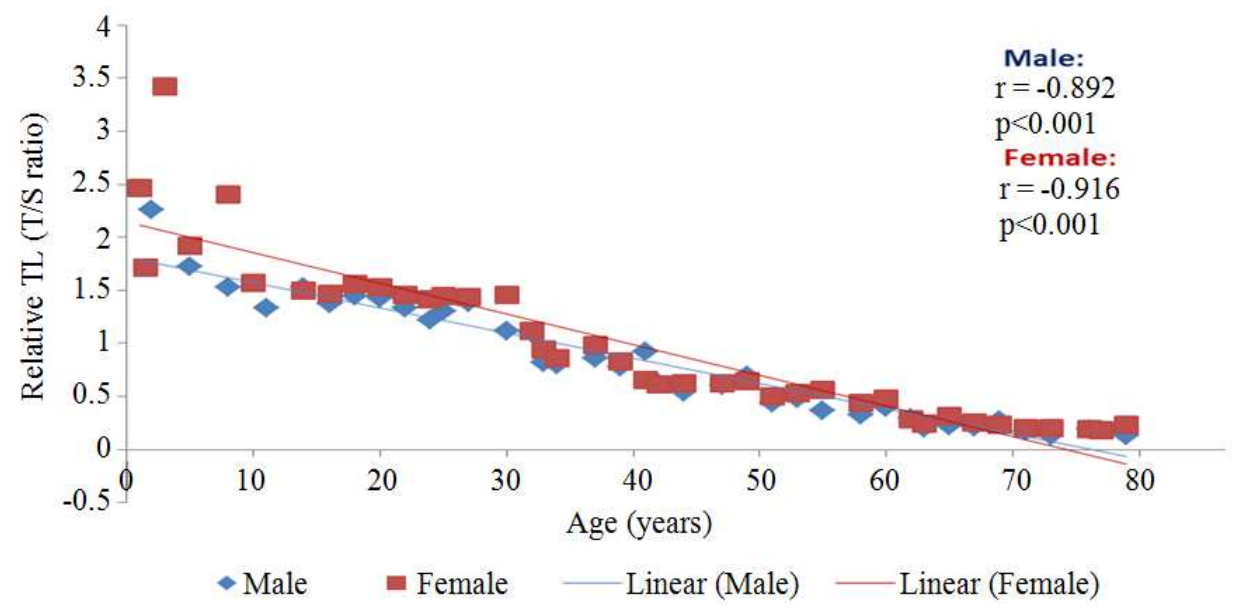

Fig. 3. Scatter plot showing the correlation between relative Telomere Length (TL) and age of all individuals included in the study, according to gender distribution; among males $(n=40, r=-0.892)$ and females $(n=40, r=-0.916)$ and $p<0.001$ for both males and females

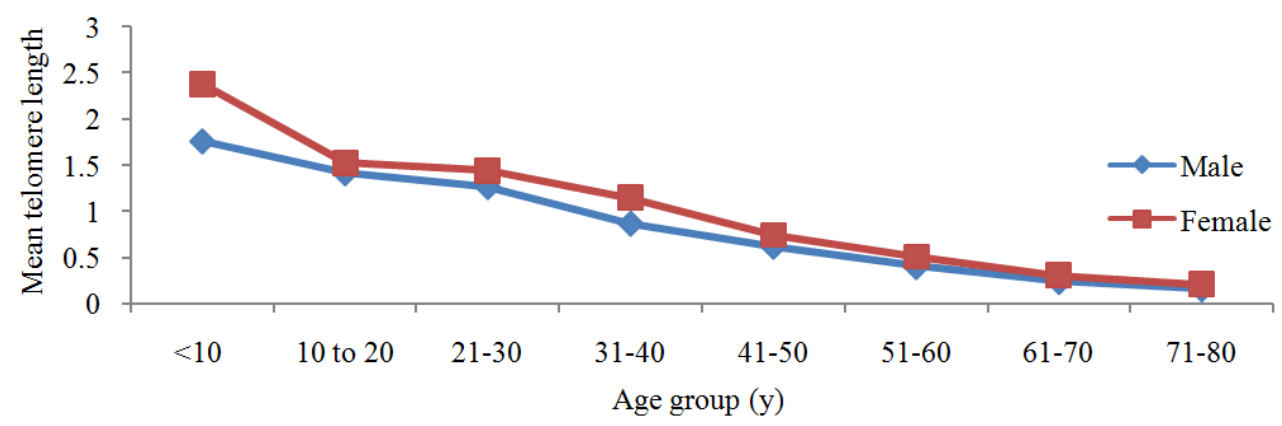

Fig. 4. Scatter plot showing the relation between mean relative telomere length (TL) and age of individuals among the studied eight sub-groups (decades of life), according to gender distribution

Correlation between the Relative TL and Age of the Individuals Included in the Study, According to the Gender Distribution

In the present study there was a gender-specific difference in relative TL; it was significantly $(\mathrm{p}<0.001)$ longer in females than males of the corresponding age among all studied individuals. When the studied individuals were classified in to eight age groups representing the decades of life, the mean relative TL was significantly $(p<0.05)$ longer in females than males, except in age groups $(<10$ years, 31-40 years and 41-50 years) which was insignificantly $(p>0.05)$ longer in females than males, as shown in Fig. 3 and 4. 
Table 2. Regression analysis for prediction of age from relative telomere length with the formula for age prediction:

\begin{tabular}{lllllll}
\hline Variables & $\begin{array}{l}\text { Equation } \\
\left(\mathrm{Y}=\mathrm{b}_{0}+\mathrm{bX}\right)\end{array}$ & $\pm \mathrm{SEE}$ & $\mathrm{R}^{2}$ & Adjusted $\mathrm{R}^{2}$ & $\mathrm{t}$-value & $\mathrm{p}$-value \\
\hline Model for total sample & $\mathrm{Y}=66.9-28 \mathrm{X}$ & \pm 10.14 & 0.815 & 0.813 & 36.30 & $<0.001$ \\
Model for males & $\mathrm{Y}=65.3-27.05 \mathrm{X}$ & \pm 10.81 & 0.796 & 0.790 & 24.30 & $<0.001$ \\
Model for females & $\mathrm{Y}=68.8-29.1 \mathrm{X}$ & \pm 9.59 & 0.839 & 0.835 & 27.04 & $<0.001$ \\
\hline
\end{tabular}

$\mathrm{Y}=$ the predicted variable (Age), $\mathrm{b}_{0}=$ constant (intercept of the regression line), $\square=$ regression coefficient (Slope of the regression line), $\mathrm{X}=$ Telomere length. SEE, Standard Error of Estimate, $\mathrm{R}^{2}$ : Coefficient of determination, adjusted $\mathrm{R}^{2}$ : (the adjusted value was used as unadjusted $\mathrm{R}^{2}$ usually overestimate the association)

\section{Regression Analysis for Prediction of Age from the Relative TL and the Formula (Equation) for Age Prediction}

A regression analysis was done and the relationship between relative $T L$ and age had an $R^{2}$ value of 0.815 for the total individuals, 0.796 for males and 0.839 for females. The present study developed a formula (equation) to calculate the age of the each individual enrolled in the study from the relative TL $(\mathrm{Y}=66.9$ $28 \mathrm{X}$ ) and another two separate equations for males and females $(\mathrm{Y}=65.3-27.05 \mathrm{X}$ and $\mathrm{Y}=68.8-29.1$ respectively), (Y: Age in years; X: Relative TL). To evaluate the accuracy of this equation; the actual ages of the subjects were compared with estimated ages using the mean prediction error (ME), which was 9.92 years for the total individuals, 10.2 years for males and 9.01 years for females. The standard error of estimate was \pm 10.14 years for the total individuals, \pm 10.81 years for males, \pm 9.59 years for females, as illustrated in Table 2 .

\section{Discussion}

When there is no a suspect to compare his/her DNA with the DNA extracted from a biological evidence left in a crime scene, it would be useful to predict what the person of interest looks like, e.g., (age, gender, ethnicity, etc.) by analyzing DNA (Hewakapuge et al., 2008).

So far, most common macroscopic methods of age identification are based on examination of dental and skeletal development. However, these methods are often qualitative and their accuracy is much reduced in adulthood (Cameriere et al., 2007). In addition, these methods cannot be practically applied to samples carried no morphologic information such as bloodstain and parenchyma (Tsuji et al., 2002).

So, estimation of the individual age using techniques of molecular biology, such as those based on Telomere Length (TL) would be of importance in forensic investigations (Ren et al., 2009).

The fact that telomere shortening occurs leads to the hypothesis that by measuring their length, a correlation could be made to the age of the suspect (Karlsson et al., 2008; Zhu et al., 2011).

The present work clearly illustrated that the relative TL (T/S ratio after normalization to single copy gene) significantly shortened with aging, among all individuals included in the study with a correlation coefficient " $\mathrm{r}$ " = $-0.903(p<0.001)$ and also showed a highly significant $(p<0.001)$ decrease in mean relative TL among the different age sub-groups.

These results were consistent with the previous observations of Guan et al. (2007), Hewakapuge et al. (2008) and Kimura et al. (2008) who confirmed that the length of telomeres decreased with age.

Figura et al. (2009) concluded that telomere shortening occurs as a consequence of proliferation along with each cell division, because of the endreplication problem of DNA-polymerase.

Various studies reported different correlation coefficient " $r$ " values of this significant negative correlation between TL and age; Nordfjall et al. (2005) in Sweden $(\mathrm{r}=-0.233, \mathrm{p}<0.01)$; Hewakapuge et al. (2008) in Australia $(\mathrm{r}=-0.185, \mathrm{p}<0.05)$, Hoffmann et al. (2009) in Germany $(\mathrm{r}=-0.601, \mathrm{p}<0.05)$ and Zubakov et al. (2010) in Netherlands $(r=-0.987, p<0.01)$, all used a quantitative real-time PCR method to measure the TL.

Meanwhile, others used the Terminal Restriction Fragments (TRF) length method to measure the TL, as Tsuji et al. (2002) and Takasaki et al. (2003) in Japan; $r$ $=-0.832$ and -0.749 respectively and $\mathrm{p}<0.01$.

Ren et al. (2009) in China who recorded a correlation coefficient " $\mathrm{r}$ " value $=-0.913$ and $\mathrm{p}<0.01$, Hewakapuge et al. (2008) explained the differences in the observed " $r$ " values as a result of differences in ethnicity, sample size, laboratory conditions in each study and not be due to differences in measuring TL in different methods.

So we selected the relative TL measurement by ratio of Telomer Hexamer Repeat (THR) copy number normalization to Single Copy Gene (SCG) ${ }_{3} 6 \mathrm{~B}_{4}$ in order to overcome these differences.

Ballantyne (2007) and Haussmann and Mauck (2008) stated that there were many conflicting reports regarding the reliability and reproducibility of TL as a molecular tool for age estimation.

The present study found that estimation of human age based on the relative TL measured by the real-time quantitative PCR may be a useful method for age prediction, especially when there is no morphologic information in the biological sample. Meanwhile it could 
only give a rough estimation of age or could be assigned to an age interval, as the age prediction value " $\mathrm{R}$ " " was 0.815 and the estimated standard error of age prediction was still quite high (around \pm 10 years; \pm 10.14 in total sample, \pm 10.81 in males and \pm 9.59 in females) to be used with certainty in forensic investigations.

These results were in accordance with Zubakov et al. (2010) in Netherlands, who confirmed that age estimation based on TL measured by quantitative PCR method was expected to provide a useful investigative tool in forensic practice, the recorded $R^{2}=0.836$ and the standard error of the estimate \pm 8.9 years.

Meissner and Ritz-Timme (2010) concluded that TL can only be assigned to an age interval, with very limited accuracy, so it may be a complementary method for age estimation in soft tissues.

In contrast Baird et al. (2005; Hewakapuge et al., 2008; Karlsson et al., 2008) confirmed that age estimation based on telomere shortening measured with real-time PCR is not appropriate for age estimation in forensic practice, as there was a relatively large variation between individuals, e.g., in the study of Karlsson et al. (2008), $\mathrm{R}^{2}=0.3$ with standard error of age prediction estimated to be much higher as \pm 22 years, while in the study of Hewakapuge et al. (2008), $\mathrm{R}^{2}$ value was 0.037 which was significantly low.

In the present work, the correlation coefficient " $r$ ", the regression $\left(R^{2}\right)$ values between TL and age were higher and the estimated standard error of age prediction was much lower than in some previous studies, probably due to the inclusion and exclusion criteria used to eliminate some factors that may affect TL such as inheritance, ethnicity and chronic diseases. Although the present study still detected some interindividual variations in telomere lengths that must be considered when applying this method of age estimation. For example there were inter-individual variations between individuals of the same age and some of the older individuals had a longer telomere length than younger individuals.

Hewakapuge et al. (2008) in Australia when they analyzed the TL of non-related Caucasians to exclude the effects of ethnicity and inheritance on TL, the correlation coefficient " $r$ " value increased $(r=-0.233, p<0.05)$ and also age prediction accuracy increased to $5.45 \%$.

Karlsson et al. (2008) stated that factors causing the variability in the TL among individuals may arise from the TL at birth and many other competing set of positive and negative factors throughout life, such as age, gender, race, disease, lifestyle, cigarette smoking, stress and an up-regulation of the immune system (i.e., infection).

Brouilette et al. (2007) and Salpea et al. (2010) confirmed that oxidative stress conditions has been found to accelerate telomere shortening and has been linked to psychological disorders, diabetes, inflammation and vascular diseases.

Saeed et al. (2012) stated that despite the fact that many pathological diseases have been found to cause telomere shortening, the direct mechanisms for these effects remain unknown.

Tsuji et al. (2002) found that dried blood stains stored for 5 months revealed a mean TL 500 bp shorter than that of freshly drawn blood samples from the same individuals. These results may be due to the use of absolute quantitation of Terminal Restricted Fragment TRF lengths.

The gender must be considered when an individual age is estimated based on telomere shortening; the present study confirmed that there was a gender-specific difference in relative TL; it was significantly $(p<0.001)$ longer in females than males of the corresponding age among all studied individuals. When the studied individuals were classified into eight age groups representing the decades of life, the mean relative TL was significantly $(p<0.05)$ longer in all females than males, except in age groups $(<10$ years, $31-40$ years and 41-50 years) which was insignificantly $(\mathrm{p}>0.05)$ longer in females than in males.

Hoffmann et al. (2009) found that women have significantly longer telomeres compared to the male population and referred that to the expression of the estrogen receptors in the female cells. Effros et al. (2005) showed that the treatment of T-lymphocytes with estrogen enhances telomerase activity in these cells and hence prevents telomeres from rapid shortening, as occurred in females. Also Nordfjall et al. (2005) found that males lost TL rapidly than females; 25 bp per year compared to 16 bp per year loss in women.

Ren et al. (2009) reported that TL was significantly longer in females than in males, specially, in two age groups (5-14 years old and 55-64 years old). However, telomere length did not differ between male and female newborns.

\section{Conclusion}

The PCR method presented here was to avoid measuring Terminal Restriction Fragment (TRF) lengths and focus instead on method that determines the relative quantities of the Telomeric Hexamer Repeats THR.

Real-time quantitative PCR assay is simple, rapid and readily scalable to achieve a high throughput of samples.

Estimation of human age based on the relative TL measured by real-time quantitative PCR may has been proved as a method for age prediction especially when there is no morphologic information in the biological sample, although the estimated standard error of age 
prediction in this study was quite high ( \pm 10 years) to be used with certainty in forensic investigations.

Inter-individual variations in relative TL and variability among the gender must be also considered when applying this method.

So, this method could only give a rough estimation of age and it may be a complementary method for age estimation in soft tissues.

\section{Recommendations}

- Large scale studies with a big sample size in population are recommended before its application in forensic practice

- A study exploring the correlation between single chromosome TL and age may better determine the exact strength of the correlation between age and $\mathrm{TL}$ and may reduce the individual variations

- It is critical to know which cells and chromosomes are susceptible to telomerase activity and the effect of telomerase activity on TL

- Studies those apply the same technique on different biological samples including dried blood spots are recommended.

\section{Acknowledgment}

Our deep gratitude and thanks to all members staff in Molecular Biology Unit, Benha Faculty of Medicine, Benha University, for their great help and cooperation. www.fmed.bu.edu.eg.

\section{Author's Contributions}

Naglaa F. Alhusseini: Molecular biology techniques, analysis and interpretation of data, revision the article and corresponding author.

Abdelmonem G. Madboly: Conception and design, samples collection, analysis and interpretation of data, statistical analysis and drafting the article.

\section{Ethics}

We confirm that this manuscript has not been published elsewhere and is not under consideration by another journal. Each author confirms the manuscript represents honest work. All authors have approved the manuscript. Each author agrees with the order in which his name appears on the title page.

\section{References}

Alaeddini, R., S.J. Walsh and A. Abbas, 2010. Forensic implications of genetic analyses from degraded DNA-a review. Foren. Sci. Int. Genet., 4: 148-157. DOI: 10.1016/j.fsigen.2009.09.007
Alhusseini, N.F., A.I. Ali, A.M.A. Abul-Fadl, A.A. Abu-Zied and S.M. El-Taher, 2014. Gene expression of FADS2 mRNA linked to intelligence in exclusively breast milk fed preterms. Am. J. Biochem. Biotechnol., 10: 267-274. DOI: 10.3844/ajbbsp.2014.267.274

Baird, D.M., B. Britt-Compton, J. Rowson, N.N. Amso and L. Gregory et al., 2005. Telomere instability in the male germline. Hum. Mol. Genet., 15: 45-51. DOI: $10.1093 / \mathrm{hmg} / \mathrm{ddi} 424$

Ballantyne, J., 2007. Final report: The determination of the physical characteristics of an individual from biological stains. Nat. Instit. Just.

Boulay, J.L., J. Reuter, R. Ritschard, L. Terracciano and R. Herrmann et al., 1999. Gene dosage by quantitative real-time PCR. Biotechniques, 27: 228-232. PMID: 10457820

Brouilette, S.W., J.S. Moore, A.D. McMahon, J.R. Thompson and I. Ford et al., 2007. Telomere length, risk of coronary heart disease and statin treatment in the West of Scotland primary prevention study: A nested case-control study. Lancet, 369: 107-114. DOI: 10.1016/S0140-6736(07)60071-3

Cameriere, R., L. Ferrante, M.G. Belcastro, B. Bonfiglioli and E. Rastelli et al., 2007. Age estimation by pulp/tooth ratio in canines by peri-apical x-rays. J. Foren. Sci., 52: 166-170. DOI: $10.1111 /$ j.1556-4029.2006.00336.x

Cawthon, R.M., 2002. Telomere measurement by quantitative PCR. Nucleic Acids Res., 30: 1-6. DOI: $10.1093 /$ nar/30.10.e47

Dawson, S.B. and R. Trapp, 1994. Basic and Clinical Biostatistics. 2nd Edn., Hall International Inc.

Effros, R.B., M. Dagarag, C. Spaulding and J. Man, 2005. The role of $\mathrm{CD}^{+}$T-cell replicative senescence in human aging. Immunol. Rev., 205: 147-157. DOI: 10.1111/j.0105-2896.2005.00259.x

Figura, G.V., D. Hartmann, Z. Song and K.L. Rudolph, 2009. Role of telomere dysfunction in aging and its detection by biomarkers. J. Mol. Med., 87: 1165-1171. DOI: 10.1007/s00109-009-0509-5

Guan, J.Z., T. Maeda, M. Sugano, J. Oyama and Y. Higuchi et al., 2007. Change in the telomere length distribution with age in the Japanese population. Mol. Cell Biochem., 304: 353-360. DOI: $10.1007 / \mathrm{s} 11010-007-9518-2$

Haussmann, M.F. and R.A. Mauck, 2008. Technical advances: New strategies for telomere-based age estimation. Mol. Ecol. Resour., 8: 264-274. DOI: $10.1111 /$ j.1471-8286.2007.01973.X

Hewakapuge, S., R.A.H. Oorschot, P. Lewandowski and S. Baindur-Hudson, 2008. Investigation of telomere lengths measurement by quantitative real-time PCR to predict age. Legal Med., 10: 236-242. DOI: 10.1016/j.legalmed.2008.01.007 
Hoffmann, J., Y. Erben, A.M. Zeiher, S. Dimmeler and I. Spyridopoulos, 2009. Telomere lengthheterogeneity among myeloid cells is a predictor for chronological ageing. Exp. Gerontol., 44: 363-366. DOI: 10.1016/j.exger.2009.02.006

Karlsson, A.O., A. Svensson, A. Marklund and G. Holmlund, 2008. Estimating human age in forensic samples by analysis of telomere repeats. Foren. Sci. Int. Genet. Suppl. Series, 1: 569-571. DOI: 10.1016/j.fsigss.2007.10.153

Kelly, H., J.A. Bright, J.S. Buckleton and J.M. Curran, 2013. A comparison of statistical models for the analysis of complex forensic DNA profiles. Sci. Just., 54: 66-70. DOI: 10.1016/j.scijus.2013.07.003

Kimura, M., J.V. Hjelmborg, J.P. Gardner, L. Bathum and M. Brimacombe et al., 2008. Telomere length and mortality: A study of leukocytes in elderly Danish twins. Am. J. Epidemiol., 167: 799-806. DOI: $10.1093 / \mathrm{aje} / \mathrm{kwm} 380$

Lynnerup, N., H. Kjeldsen, R. Zweihoff, S. Heegaard and C. Jacobsen et al., 2010. Ascertaining year of birth/age at death in forensic cases: A review of conventional methods and methods allowing for absolute chronology. Foren. Sci. Int., 201: 74-78. DOI: $10.1016 /$ j.forsciint.2010.03.026

Meissner, C. and S. Ritz-Timme, 2010. Molecular pathology and age estimation. Foren. Sci. Int., 203: 34-43. DOI: 10.1016/j.forsciint.2010.07.010

Nakagawa, S., N.J. Gemmell and T. Burke, 2004. Measuring vertebrate telomeres: Applications and limitations. Mol. Ecol., 13: 2523-2533. DOI: 10.1111/j.1365-294X.2004.02291.x

Nordfjall, K., A. Larefalk, P. Lindgren, D. Holmberg and G. Roos, 2005. Telomere length and heredity: Indications of paternal inheritance. Proc. Natl. Acad. Sci. U.S.A., 102: 16374-16378. DOI: $10.1073 /$ pnas.0501724102

Price, L.H., H. Kao, D.E. Burgers, L.L. Carpenter and A.R. Tyrka, 2013. Telomeres and early-life stress: An overview. Biol. Psych., 73: 15-23. DOI: 10.1016/j.biopsych.2012.06.025
Ren, F., C. Li, H. Xi, Y. Wen and K. Huang, 2009. Estimation of human age according to telomere shortening in peripheral blood leukocytes of Tibetan. Am. J. Foren. Med. Pathol., 30: 252-255. DOI: 10.1097/PAF.0b013e318187df8e

Saeed, M., R.M. Berlin and T.D. Cruz, 2012. Exploring the utility of genetic markers for predicting biological age. Legal Med., 14: 279-285. DOI: 10.1016/j.legalmed.2012.05.003

Salpea, K.D., P.J. Talmud, J.A. Cooper, C.G. Maubaret and J.W. Stephens et al., 2010. Association of telomere length with type 2 diabetes, oxidative stress and UCP2 gene variation. Atherosclerosis, 209: 42-50.

DOI: $10.1016 /$ j.atherosclerosis.2009.09.070

Takasaki, T., A. Tsuji, N. Ikeda and M. Ohishi, 2003. Age estimation in dental pulp DNA based on human telomere shortening. Int. J. Legal Med., 117: 232-234. DOI: $10.1007 / \mathrm{s} 00414-003-0376-5$

Thomas, P., N.G.O. Callaghan and M. Fenech, 2008. Telomere length in white blood cells, buccal cells and brain tissue and its variation with ageing and Alzheimer's disease. Mech. Ageing Dev., 129: 183-190. DOI: 10.1016/j.mad.2007.12.004

Tsuji, A., A. Ishiko, T. Takasaki and N. Ikeda, 2002. Estimating age of humans based on telomere shortening. Foren. Sci. Int., 126: 197-199. DOI: $10.1016 / \mathrm{S} 0379-0738(02) 00086-5$

Zhu, H., X. Wang, B. Gutin, C.L. Davis and D. Keeton et al., 2011. Leukocyte telomere length in healthy Caucasian and African-American adolescents: Relationships with race, sex, adiposity, adipokines and physical activity. J. Pediat., 158: 215-220. DOI: 10.1016/j.jpeds.2010.08.007

Zubakov, D., F. Liu, M.C. Van Zelm, J. Vermeulen and B.A. Oostra et al., 2010. Estimating human age from T-cell DNA rearrangements. Current Biol., 20: 970-971. DOI: 10.1016/j.cub.2010.10.022 